\title{
Automatic plant Irrigation Control System Using Arduino and GSM Module
}

\author{
S. Akwu ${ }^{\mathrm{a}}$, U. I. Bature ${ }^{\mathrm{ab} *}$, K. I. Jahun ${ }^{\mathrm{a}}$, M. A. Baba ${ }^{\mathrm{ac}}$, A. Y. Nasir ${ }^{\mathrm{a}}$ \\ ${ }^{a}$ Department of Computer and Communications Engineering, Abubakar Tafawa Balewa University Bauchi \\ (ATBU), P. M. B. 0248, Nigeria \\ ${ }^{b}$ Department of Electrical and Electronic Engineering, Universiti Teknologi PETRONAS, 32610 Bandar Seri \\ Iskandar, Perak, Malaysia \\ ${ }^{c}$ School of Electrical Engineering, Advanced RF \& Microwave Research Group, Universiti Teknologi \\ Malaysia, (UTM), Skudai Johor Bahru, 8130, Malaysia
}

Received: 15 April 2020; Accepted: 03 May 2020; Published: 08 June 2020

\begin{abstract}
The evolving information technology abridges the hardship in the daily life of consumers all over the world, hence the application of this knowledge in the irrigation field is necessary nowadays. The exponential growth of demand in food is due to the ever-evolving population of the world, thus it becomes necessary to expand the present area of cultivation. Considering the present situation of weather change due to global warming as a result of industrial activities, farming via irrigation is the reliable process of food production. Water remains the only source for survival for crop production, thus optimal management and proper use of water become pertinent with the ever-increasing land for irrigation. Arduino based automatic plant irrigation control system; provides a simple approach to automated irrigation. This work makes use of the GSM module for the notification of the user about the situation in the farm, this project aims to design and implement an automatic plant irrigation control system using Arduino and GSM module. In this proposed system, there are two main parts hardware and software units. Mechanical units which are the hardware unit comprises of instrumentation systems and watering irrigation systems. The equipment system is based on microcontroller, flow meter, moisture sensor, LCD, and GSM module. The software part comprises of C++ code, this is to enable the linkage between various modules. The main control of this system is the microcontroller unit that serves as the brain for coordinating control for various modules of the system, it synchronizes and operates the watering system and notifies the user about the condition of the field and watering section via GSM module. Implementation of this project will significantly help in a water-saving of about $30-50 \%$ as compared to the conventional watering system like the sprinkler, improve growth and discourage weeds because water will only be served to the needed area, simple method and timer-based system for automatic watering can be incorporated for efficiency.
\end{abstract}

* Corresponding author. Tel.: +2348037732580 / +601136377359

E-mail address: biusman@atbu.edu.ng 
Index Terms: Irrigation, watering system, moisture content, water control, automated irrigation.

(C) 2020 Published by MECS Publisher. Selection and/or peer review under responsibility of the Research Association of Mode rn Education and Computer Science

\section{Introduction}

The process of artificially applying a precise volume of water to the needed crops/plants at the needed time frame is known as irrigation, it's commonly used in watering plant or crop, revitalization of a dried soil in water-scarce areas and maintenance of landscapes. Among the abundant mineral resources, water is the most excessively used resource, irrigation is one of the activities that require water the most, it's an activity that was traditionally known to be done by humans, and manual method of irrigation consumes time and resources. Considering the development in engineering and technology fields, automated systems are continually evolving nowadays, thus there is a need to automate the manual means of crop/plant irrigation to go in line with the evolving trend of technology. Continuous increasing demand for food with the world population heading to around 8,501 million in 2030 [1], hence rapid development in food production method is highly needed. Suggested by [2], need for the synchronization of the world to digital design will guarantee efficiency, quality and speed, the idea was supported by [3] producing knowledge of Internet of Things (IoT), this was supported with the project proposed in [4] that uses IoT to control home appliances. Queue management was another area included in the new trends of technology, a design to help in queue management in the hospital was proposed in [5] for easy services and productivity, also the use of the ultrasonic sensor in [6] that eliminate the hazardous effect of copper wire reaffirmed the significance of emerging technology and image processing is also another add up to the trend [7]. The use of sensors for detecting inputs from the physical surroundings further eases the way of doing things [8], such as pressure, heat, motion, etc. Furthermore, there is a need to incorporate the new technology in all aspects of the endeavor, since the use of software in the security and monitoring system like robots has gained tremendous success [9].

Africa has climate ranges that receive few centimeters of rains in a year, thus its land requires a large amount of water for dry season farming. Nigeria also has some areas with few or little rainfall in a year and the economy is also dependent on agriculture and animal production, due to the lack of technical know-how it cannot fully utilize its abundant land area. Low rainfall and lack of Dam or land-water reservoir systems are few among many reasons [10]. Thus, some lands need to be rehabilitated through the emerging technology for optimal use, the traditional method needs to be updated and more reservoirs also needs to be reconstructed. This proposed project is an automated plant irrigation control system that notifies users of the situation at the farm, this was aimed at reducing the manual traditional method of plant irrigation and minimizing water wastage. This will serve as a transition from the manual to the automated method of irrigation, it can be applied not just in the farming but in schools or institutions, industries, houses for landscapes watering systems. The watering system is controlled via the soil moisture sensor that senses the percentage of water present in the soil and update to the microcontroller for watering and sends of notification to the owner, this project focuses on reducing excessive human interference in the process of irrigation, also reduce water waste and inform the owner about the situation in the farm. In this section, methodology and materials for the design were discussed, simulated results and soil moisture sensor analysis were also added, and finally, the conclusion stated the main aim and objectives with the future improvements. 


\section{Literature Survey}

Water needs to be managed as it was popularly known "water is life", a system was proposed using an ultrasonic sensor to detect tank water level and notify owner for appropriate action [11], this reveals the significance of notification system, but the system is just part of this proposed system (sending a notification to users). Environmental conditions like light intensity, temperature, humidity, moisture contents, $\mathrm{pH}$ condition, water nutrient solution, irradiation or $\mathrm{CO} 2$ concentration and vapor pressure play some vital roles in the survival and growth of plant or crops, thus accurate knowledge and monitoring of these parameters could greatly help in increase in production and bumper harvest. This was supported in [12], and environmental parameter evaluation and control in greenhouse cultivation of tomatoes were proposed, From this research, it can be inferred that few factors need environmental regulation, also this proposed system required environmental regulation. The use of aeroponics as one of the modern method for cultivation was reviewed in [13], the research provides good information on fault and detection of environmental parameters using wireless sensors for monitoring and control of the system remotely. Akin cellatoglu and Balasubramanian Karuppanan has provided the farmers with a full irrigation solution based on the Wireless Sensor Network (WSN) [14]. Using low-cost sensor nodes with reduced power consumption, the automated irrigation system will reduce water waste and is cost-effective. The Telos B mote and appropriate sensors/actuators are used to deploy a node. Field nodes are used to measure soil humidity and temperature levels. Climate nodes track climate changes, and when appropriate, the nodes connected to actuators are used to control the irrigation valve opening. Water scarcity in some area is seriously causing a setback in food production, A. Singh et al proposed an idea on how to minimize the water use in the farm, in irrigation about 60 or $70 \%$ of water is usually lost through application and delivery to the farm, it was noted that use of the efficient process, good management, and good practices adoption are key to water conservation and good production [15].

It was well known that drip irrigation minimizes water wastage, a microcontroller-based system that uses sensors for notification, and control was proposed in [16]. This further agrees with the design mentioned in [15] and also in line with what this proposed system intents. Wheat crop cultivation is a type of irrigation that is usually done in the dry season period especially in Africa and some part of Asia where rainfall is seasonal, Soil Moisture sensor-based system was developed in 2011 [17] to monitor soil moisture via an intelligent irrigation setup that was compared with the traditional manual method. T. Boutraa et al. in 2011 also proposed that water stress is a key factor for hindering growth and development of crop/plant production in areas with less rainfall in a year known as semi-arid and arid regions, they compared the use of intelligent irrigation system against the manual irrigation process [18], this is one of the intents of this proposed system. Their results show that apart from the minimum water wastage an improved in production and performance of plants under the automated irrigation system was recorded. Y. By integrating a center pivot irrigation system with wireless underground sensor networks[19], Dong et al identified an autonomous precision irrigation system. The wireless underground sensor assisted center pivot system can provide autonomous irrigation management capabilities by using wireless underground sensors to track the soil conditions in real-time. Experiments were performed with a pivot irrigation system for the hydraulic drive and center continuous-movement. Mahir Dursun and Semih Ozden suggested an efficient water use system using a solar-powered drip irrigation system in an orchard by the pump power[20]. Artificial Neural Networks (ANN) analyzes the content of soil moisture to provide an even distribution of water for the appropriate position. That will prevent excessive irrigation and reduce the demand for water. This method decreases the routine usage of water and energy consumption by 38 percentage points for the orchard. This was also supported by [21, 22] where similar processes were proposed and shown to be productive. 
Organic, gases, chemical and hazardous substances are increasingly produced day by day and their huge quantities are unsafe to human and environment, a system was proposed [23] to detect the leakages of gas that has an integrated module with embedded control. Another approach was proposed [24] for detecting motion along with a pipeline setup, the system notifies personnel via a multi-sensor setup of vibration and sound sensor. This idea was supported by [25] using sensors that help in pollution monitoring of petroleum products that could prevent any disaster.

Because of the above, it is obvious that monitoring natural resources via sensor application is necessary for intruder, theft and natural disaster prevention, this is in line with the environmental parameter monitoring for better plant or crop irrigation process. Therefore, it clearly shows that using sensor-based modules for water leakages or water use, liquid, and gas monitoring is pertinent for safety, production, operation, and development.

\section{Materials and Methodology}

The research method employed in this work is the applied research method with the emphasis paid in solving the problem faced during the manual irrigation water system in the farm using the available tools and methods. The research focuses on Quantitative research approach for solving the identified problem of manual irrigation system. This system operates using four key units, the watering unit that is supplied by the pump, the messaging unit which is done using SIM800 TTL GSM module, the SIM800 is preferred because it provisions Quad-band GSM/GPRS module which delivers 850/900/1800/1900MHz, it transmits data, voice, and SMS with low power consumption, transmit TTL output, compact in size and simple use as plug and play in GSM Modem, the moisture sensing unit that is done via the soil moisture sensor, it senses and sends the output to the control unit that is coordinated by the microcontroller unit. The control unit can control the watering process depending on the condition or output response send by the moisture sensor. The complete system block diagram is shown in fig. 1.

The Atmel328 microcontroller controls the entire process. Moisture sensor senses the moisture level in the soil and watering system is done by the water pump that helps in supplying the water to the reservoir and farm, the GSM module provides the messaging platform that informs the farmer of the status of the moisture content and situation in the irrigation.

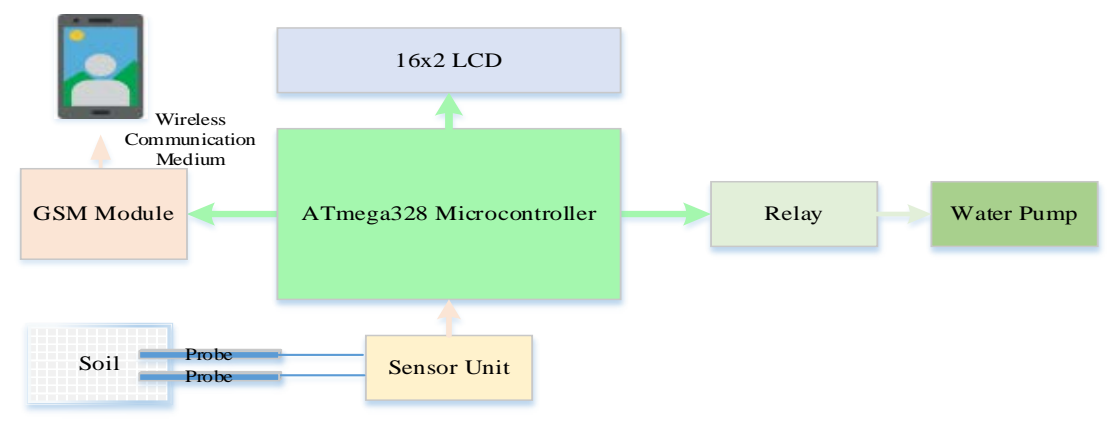

Fig. 1. System Block Diagram 


\subsection{Hardware Development and Analysis}

The method for hardware development and analysis is stated in this section.

\subsubsection{Power Unit}

Electrical power is the rate of electrons moving which generates electricity. To carry out such operations, many goods need electrical power due to the electronic era. Each circuit runs on a different voltage, some circuits run on $5 \mathrm{~V}, 9 \mathrm{~V}$, etc. So if an ATMEGA 16bit microcontroller is used this project will use $5 \mathrm{~V}$ and $12 \mathrm{~V}$, then it will require a 5V power supply as the operating voltage for ATMEGA 16 microcontroller is 5V. If a voltage greater than $5 \mathrm{~V}$ is applied then it can damage the microcontroller. To prevent this we still use a $5 \mathrm{~V}$ power supply for circuits with microcontrollers. Below is a dc power supply block diagram, in which four phases are shown in fig. 2.

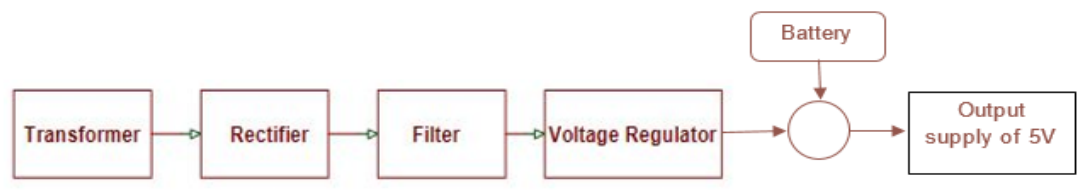

Fig. 2. Power Supply Block Diagram

\subsubsection{Relay Interfacing}

This device includes a transistor (BC109) that acts as a switch, DC generator, and relay. For switching applications the common NPN transistor emitter configuration is typically used, thus this project uses NPN transistor. Many relays use the electromagnetism concept to operate but even others such as a solid-state are employed. A contactor is a relay type that can handle a high power required directly to control an electric motor or other loads. Whenever a relay is powered out of a network that has sensitive components such as integrated circuits or transistors, a diode is often inserted across the relay coil to avoid the relay from damaging the circuit. The relay circuit/connection is shown in the diagram. 3.

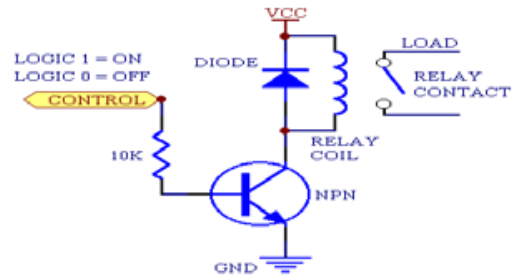

Fig. 3. Simple Relay Interfacing

\subsubsection{Sensing Unit}

The soil moisture sensor has been interfaced with the Arduino via a digital PCB drive. A digital potentiometer is available on the PCB drive. When connected in digital mode, the digit is used to alter the sensitivity of the sensor. There are four link pins on the PCB drive. The analog configuration is more robust than the digital configuration. The PCB drive pin A0 was connected as shown in fig. 4 to the Arduino analog pin A0. 4. 


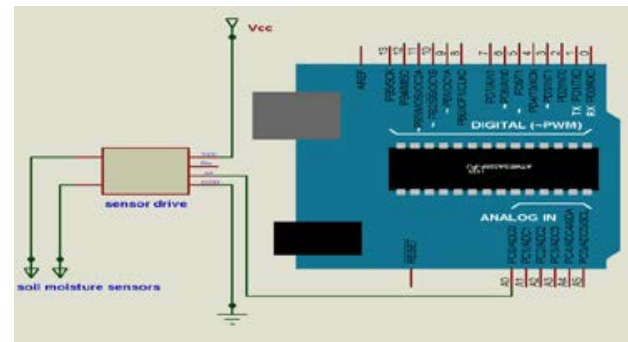

Fig. 4. Sensor Interfacing with Arduino

The Arduino analog pin A0 sensor response was resistance. The current resistance between the sensor samples varies with soil moisture and soil type. The current movement through the sensor samples was measured in equation 1 for different soils and different soil moisture levels.

$$
I_{\text {out }}=\frac{V c c}{\{\text { Soil Resistance value }(R S)\}}
$$

\subsubsection{Output Unit}

To achieve the desired effective display, a screen LCD of 16x2 display was used. A four-bit mode data select configuration using pins 2, 3, 4, and 5 of the Arduino were connected to the LCD data lines D2, D3, D4, and D5 respectively. GND is a ground pin that was connected to $16(\mathrm{~K})$, and $15(\mathrm{~A})$ to Vcc power supply pin. The enable pin (Enable) of the LCD connected to the Arduino pin 11 digital pin, the GND of the Arduino connected to R/W of the LCD, and pin 12 of the Arduino connected to register select pin (RS), fig. 5 shows the physical interface between the display unit and the Arduino.

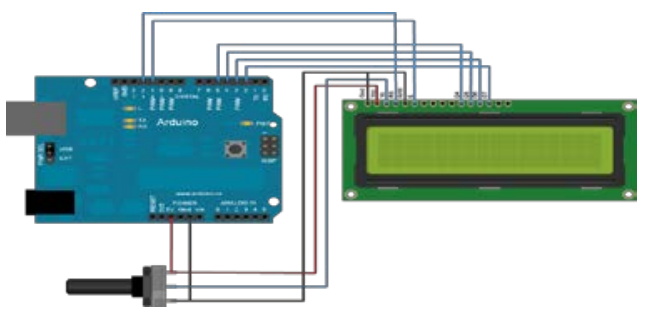

Fig. 5. Display (LCD) Interface

\subsubsection{Water Pump Interface with Arduino Uno}

The water pump is one of the important units of this project, it supplies water to the reservoir and farm. The water pump in this project is the well-known $240 \mathrm{~V}$ AC power, but the sensing and microcontroller units were powered by $5 \mathrm{~V}$ DC. Thus, a relay that can serve as an isolation unit for the interfacing between the units was chosen as SLT73-5D-IZ \%V DC relay. An NPN transistor was used to connect the relay to the microcontroller unit with a model number $2 \mathrm{~N} 4123$, and a pull-down resistor was used to protect the transistor. Back e.m.f. is another issue associated with the microcontroller, but a switching diode was used across the relay for this purpose, fig. 6 shows the schematic physical connection of this setup. 


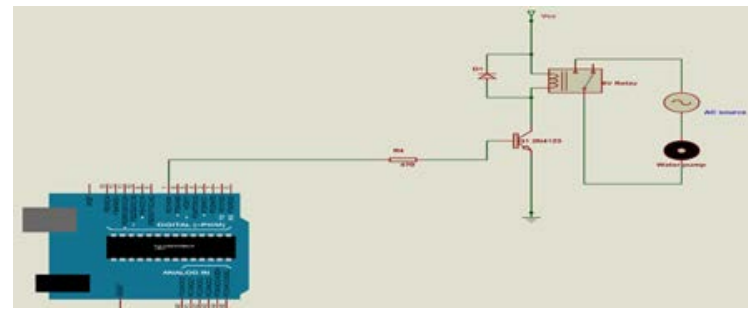

Fig. 6. Physical Interface of the Water Pump and the Arduino

\subsection{Software Development and Analysis}

The software design section is presented in this section, $\mathrm{C}++$ programming language was used for the programming of the Arduino Uno, and simulation for the complete hardware system was done using proteus model tool.

\subsubsection{Proteus ISIS Circuit Simulator Software}

Proteus helps engineers to model real circuit simulation designs interactively. It features a range of simulators for common microcontrollers and an interactive set of models for peripheral devices including LEDs and LCD screens, keypads, and more. Full microcontroller systems can be simulated and the software designed for them without physical prototype access. Models such as Atmega328, LED, LCD panel, switches, bowl, relays, resists, resistors and sources are used and tests have been verified by hardware performance. This is achieved by simulating software Proteus ISIS software.

\subsubsection{Arduino Uno Programming}

Arduino Uno is programmable with Arduino IDE tools. The Arduino microcontroller is an easy-to-use but an efficient single-board computer with significant popularity in the hobby and professional market. The Arduino is open-source, meaning hardware is fairly priced and free development software.

Algorithm of the program is stated below to show the processes flow of the system:

Step 1: Start process

Step 2: Initialize the microcontroller in Arduino, start the GSM module

Step 3: Read the moisture content and check the level of the water in the reservoir

Step 4: If the water level goes within the set level, do nothing. If below the level then pump water.

Step 5: If the moisture content is below the threshold then start irrigation else do nothing

Step 6: Update the farmer via GSM message about the situation on the farm.

Step 7: After the process completion update farmer about the situation

Step 8: Process return to original state and check for the moisture content

The flow chart showing process execution is shown in fig. 7, It shows processes for sensing moisture content of the soil in the farm, it notifies the farmer about the condition of the soil in the farm in case if the water is needed. 


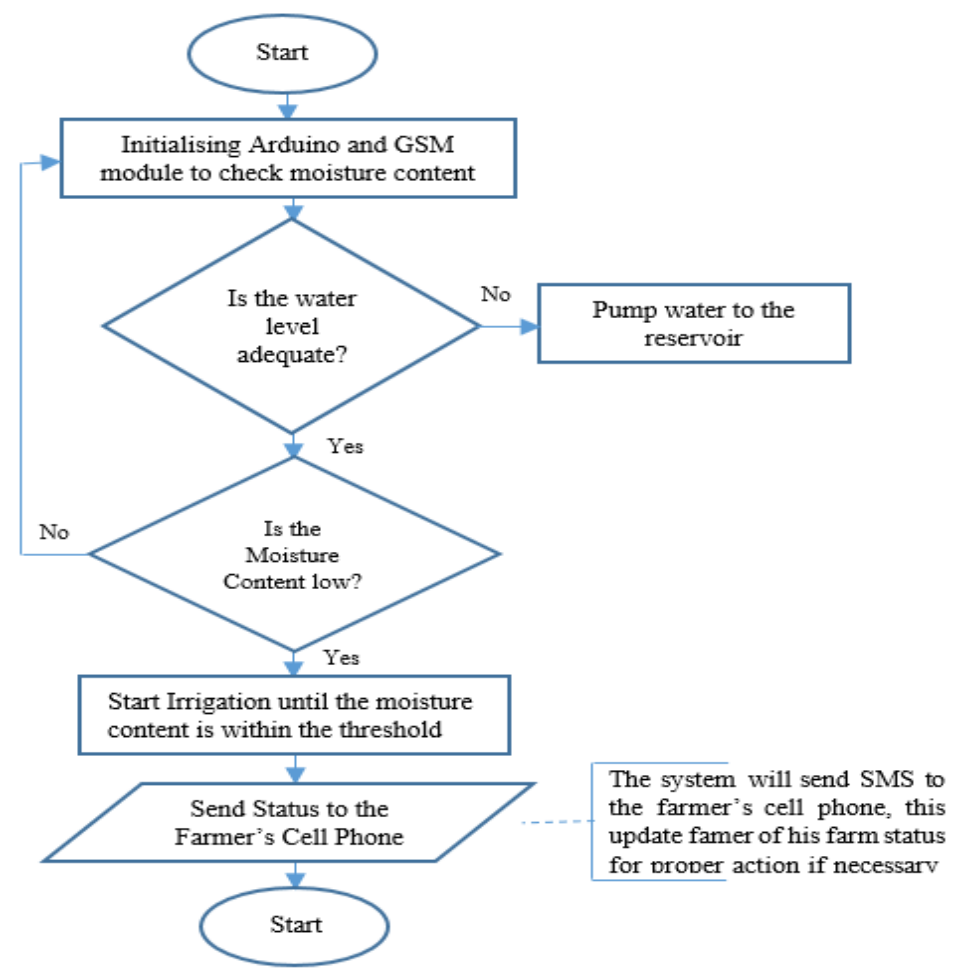

Fig. 7. Flow Chart Diagram of the System

\section{Result and Analysis}

This section explains the experiments performed on the different parts of the overall system and their respective results as well as the overall system results. To verify the system's correct functionality, each feature must be independently checked. Debugging was carried out using the simulation software Arduino Uno and Proteus LAB, each part of the code was properly debugged to ensure the correct functionality. This is a facility in the simulation software; Arduino Uno and Proteus LAB that allow you to enter the system when viewing flag settings and registers. The components of the system comprise the microcontroller (Atmel324), messaging unit via GSM module, sensing via the sensor unit and the interfacing was realized using a relay. Traditionally in the irrigation setup, lanes were usually used for water to flow along to the various route that leads to the plant section, root and this is controlled via the sensor response, and in case of the reservoir water goes below the minimum level the pump will automatically refill the reservoir to the required maximum level.

\subsection{Result Analysis of the Sensor}

The results shown in Table 1 is the soil moisture response obtained from varying the resistance of the potential divider unit to serve as the wet and dry soil sample conditions, the potential divider value chosen was up to $800 \mathrm{k} \Omega$, the value was chosen because of the sample value will range up to that much. 
Table 1. Soil Moisture Simulation Response

\begin{tabular}{ccc}
\hline Level of the Soil Moisture & $\begin{array}{c}\text { The response of } \\
\text { the sensor circuit } \\
\text { (V) }\end{array}$ & $\begin{array}{c}\text { The response of } \\
\text { the Pump circuit } \\
\text { (V) }\end{array}$ \\
\hline Under low level & 2.375 & 0 \\
Increasing but below the higher level & 3.262 & 0 \\
More than higher level & 5.265 & 10 \\
Reducing but greater than the lesser level & 4.372 & 10 \\
\hline
\end{tabular}

Fig. 8 shows the equivalent result shown in table 1 for better comprehension, this has shown that for a value of the moisture content less than the threshold the water pump will remain alert, take action as appropriate until the level goes above the required threshold.

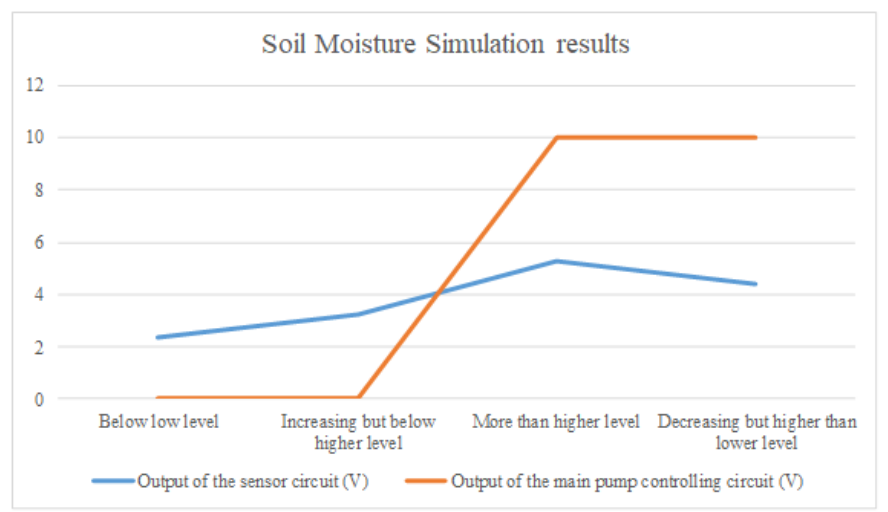

Fig. 8. Equivalent of the soil moisture simulation results

\subsection{Relay various test analysis}

The result obtained from the relay various test conditions is tabulated in table 2, the result shows the outputs of the relay during the soil moisture test. Water pump operation is controlled by the relay action and its operation depends on the state of the soil moisture as shown in table 2.

Table 2. Relay operation for various test conditions

\begin{tabular}{cccccc}
\hline $\begin{array}{c}\text { Voltage } \\
(\mathrm{V})\end{array}$ & Condition of the Soil & $\begin{array}{c}\text { State } \\
(\mathrm{Q})\end{array}$ & $\begin{array}{c}\text { Amplifier Stage } \\
(0 \text { or } 1)\end{array}$ & $\begin{array}{c}\text { Relay switch } \\
\text { Connection }\end{array}$ & $\begin{array}{c}\text { Water Pump } \\
\text { Action }\end{array}$ \\
\hline$>5$ & Over Wet & OFF & 1 & Open State & No Operation \\
$<5$ & Optionally Wet & OFF & 1 & Open State & No Operation \\
$>5$ & Optionally Dry & ON & 0 & Closed State & Operation \\
$<3$ & Fully Dry & ON & 0 & Closed State & Operation \\
\hline
\end{tabular}

\subsection{Analysis of the Soil State}


The soil moisture results were obtained and recorded as shown in table 3, the results were based on the data recorded from the Volumetric Water Content of the three samples of soil used, the red, loamy and sandy soil. The measurement was based on an equal volume of $250 \mathrm{~g}$ of each sample while slowly adding water to the soils and recording the sensor readings.

Table 3. Raw Data from the Sensor Readings

\begin{tabular}{cccc}
\hline $\begin{array}{c}\text { Water Content in the Soil } \\
\left(\mathrm{cm}^{3}\right)\end{array}$ & \multicolumn{3}{c}{ Sensor Data } \\
\hline 0 & Loamy Soil & Sandy Soil & Red Soil \\
50 & 1021 & 1022 & 1020 \\
75 & 580 & 546 & 781 \\
100 & 360 & 234 & 568 \\
125 & 237 & 243 & 295 \\
150 & 203 & 184 & 274 \\
150 & 191 & 180 & 235 \\
\hline
\end{tabular}

The data detailed in table 3 were obtained from the readings of the soil sensor and were plotted against the water of the soil as shown in fig. 8. The soil sensor produces its reading inform of resistance because of its check the resistance between the two probes. The graph shown indicates an exponential decay pattern because from the readings it was obvious that the increase in water content results in the decrease of the soil resistance until it reaches saturation point, where the increases don't show any significant effect on the resistance.

The volume of $250 \mathrm{~g}$ of the three soil samples was obtained (250g of Loamy, 250g of Red soil and 250g of the Sandy soil) and the samples were dehydrated until no moisture content was present, then slowly adding water to the sample in the range of $25 \mathrm{~cm} 3$ alternatively recording the sensor readings. According to the recorded values, the values for the dried three samples soil were almost the same, the Loamy sensor reading was 1021, Red at 1020, and the Sandy at 1022 .

On the addition of water increase from $25 \mathrm{~cm} 3$ to $50 \mathrm{~cm} 3$ an extreme reduction in the resistance was observed to a value slight above 500, and adding more water reduces the resistance the more, lowest resistance or saturation state was attained on the addition of $100 \mathrm{~cm} 3$ of water, thus the addition of more water has no or little effect on the resistance of the soil. Three distinctive states were stated as; Dry state, Wet state, and the Water-logged state, the sensor was calibrated according to these states, measurements were recorded to observe the response from the microcontroller, the pump switching was observed when the sensor reads the dried soil state via the triggering of the switch unit. 


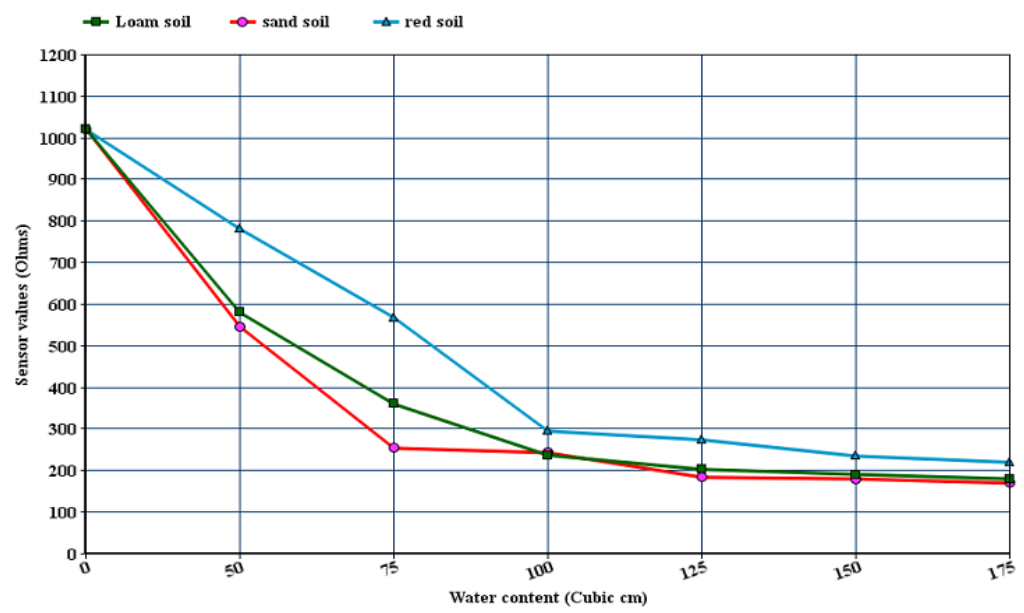

Fig. 9. Soil water content Vs sensor reading

The entire system's objective was to help farmers minimize water wastage and increase crop production since soil moisture level varies among crops, the sensor will be calibrated according to the desired crop. The system was designed to operate within the low power application, the complete system set up showing the moisture content testing process is displayed in fig. 10a and b.

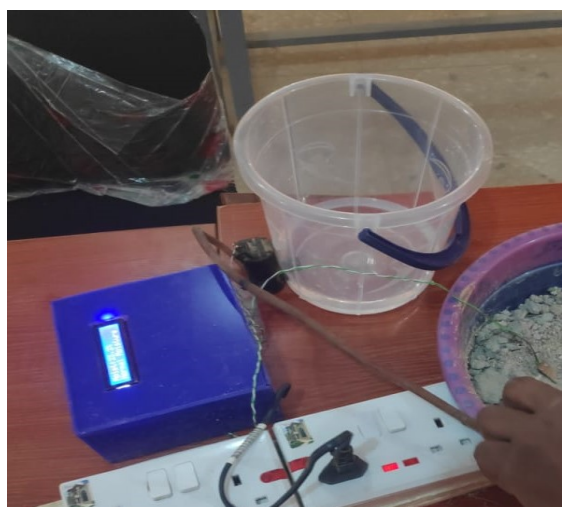

(a)

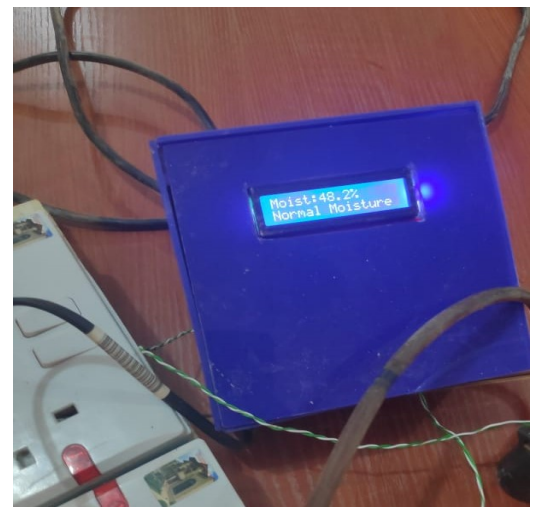

(b)

Fig. 10. Project prototype set up, (a): Testing the moisture sensor, (b): Percentage of soil moisture displayed on LCD

The soil sensor moisture works based on the amount of percentage of moisture contents present in the soil, it will be placed in that particular area for detection and sensing, its output will be feed to the control unit for appropriate action. The microcontroller controls the activities via sending control signals to other components of the system, this method will efficiently control the amount of water going to the root of the plant and avoid water blockage, saves water and minimize manual human error for improvement in production and better yield.

Results shown in table 4 indicate the reliability of the system based on the tested parameters, the tested components were Atmel328 microcontroller, motor pump, moisture sensor, and LCD. Table 4 shows the expected results obtained during the test. 
Table 4. System Testing and the expected result

\begin{tabular}{|c|c|c|c|}
\hline Test & Event & Test Description & Expected result \\
\hline 1 & $\begin{array}{l}\text { Testing the } \\
\text { microcontroller, } \\
\text { sensor and the LCD }\end{array}$ & $\begin{array}{l}\text { The microcontroller is shown to control the } \\
\text { entire system process, the sensor senses the } \\
\text { moisture content and updates to the } \\
\text { microcontroller for necessary action and } \\
\text { display }\end{array}$ & $\begin{array}{l}\text { The result/status of the moisture } \\
\text { content displayed on the LCD }\end{array}$ \\
\hline 2 & $\begin{array}{l}\text { The motor pump } \\
\text { testing }\end{array}$ & $\begin{array}{l}\text { The motor output is tested when the water } \\
\text { content is more than a higher level. When the } \\
\text { water is higher than the lower level, and when } \\
\text { below the lower level }\end{array}$ & $\begin{array}{l}\text { The water pump is OFF when lower } \\
\text { the OFF and the pump switched ON } \\
\text { when water is at the lower level }\end{array}$ \\
\hline 3 & $\begin{array}{l}\text { Atmel328 } \\
\text { microcontroller } \\
\text { speed/response test }\end{array}$ & $\begin{array}{l}\text { This determines how fast the Atmega328 can } \\
\text { perform a task }\end{array}$ & $\begin{array}{l}1 \mathrm{MIPS} \text { for } 1 \mathrm{MHz} \text {, the response to } \\
\text { the sensor system is quick and } \\
\text { appropriate as shown in the table. } 1\end{array}$ \\
\hline 4 & Moisture sensor test & $\begin{array}{l}\text { Condition of the soil at optionally dry, } \\
\text { optionally wet, fully dry and fully wet }\end{array}$ & $\begin{array}{l}\text { At dry soil the pump switched ON, at } \\
\text { optionally wet it stayed OFF, at the } \\
\text { fully wet soil the pump switched } \\
\text { OFF as shown in the table. } 2\end{array}$ \\
\hline
\end{tabular}

\section{Conclusion}

Low rainfall and lack of Dam or land-water reservoir systems are slowly dragging some lands into the state of non-irrigation in Africa. This work aims at enhancing the manual method of water irrigation process to the automated one, and stimulate the human capital development and opportunities for capacity building, it proposes a simple automated technique of plant irrigation control system with GSM notification. In this design, the Arduino is the main control of the system that coordinates the control to other system components, the soil moisture sensor senses the percentage of water in the soil and updates the percentage if it goes below the threshold value for that particular crop/plant to the microcontroller unit for the start of the watering and updates to the owner via SMS. According to the results obtained and shown, the effectiveness of the system can be enhanced. In future work, the incorporation of a web interface for remote control should be done and the system can be made to monitor the condition of the weather in the farm via the incorporation of humidity and temperature sensors.

\section{Acknowledgements}

The authors would like to acknowledge the computer and communications engineering department, Abubakar Tafawa Balewa University Bauchi (ATBU) for supporting and providing equipment until the completion of the project. Embarking.

\section{References}

[1] Islam, Sheikh Mohammad Fakhrul, and Zahurul Karim. "World’s Demand for Food and Water: The Consequences of Climate Change." In Desalination-Challenges and Opportunities. IntechOpen, 2019.

[2] Archana Rani, Naresh Grover,"Design and Implementation of control Unit-ALU of 32 Bit Asynchronous Microprocessor based on FPGA", International Journal of Engineering and Manufacturing (IJEM), Vol.8, No.3, pp.12-22, 2018.DOI: 10.5815/ijem.2018.03.02 
[3] Anusha k, U B Mahadevaswamy,"Automatic IoT BasedPlant Monitoring and Watering System using Raspberry Pi", International Journal of Engineering and Manufacturing (IJEM), Vol.8, No.6, pp.55-67, 2018.DOI: 10.5815/ijem.2018.06.05

[4] Adamu, U. I. Bature, A. Y. Nasir, A. M. Hassan, K. I. Jahun and U. S. Toro, "IOT Controlled Home Automation Technologies," 2019 2nd International Conference of the IEEE Nigeria Computer Chapter (NigeriaComputConf), Zaria, Nigeria, 2019, pp. 1-7.

[5] A. E. Seun, U. I. Bature, K. I. Jahun, A. Y. Nasir, A. M. Hassan and U. S. Toro, "Hospital Electronic Queuing Solution System," 2019 2nd International Conference of the IEEE Nigeria Computer Chapter (NigeriaComputConf), Zaria, Nigeria, 2019, pp. 1-7.

[6] Garba Suleiman. "Implementation of a Contactless Water Level Controller: Embracing Opportunities in Nigeria Computer Science NCE Curriculum", International Journal of Engineering and Manufacturing (IJEM), Vol.10, No.2, pp.41-51, 2020. DOI: 10.5815/ijem.2020.02.04

[7] U. I. Bature, Murtala A. B., A. Y. Nasir. "Evaluation of Image Detection Techniques". Journal of Multidisciplinary Engineering Science and Technology (JMEST). Vol. 2 Issue 12, 2015. pp. 3467-3472

[8] Adegoke A. O , Oluseun D Oyeleke , Mahmud B, Ajoje J. O, Sadiq Thomase," Design and Construction of an Obstacle-Detecting Glasses for the Visually Impaired", International Journal of Engineering and Manufacturing(IJEM), Vol.9, No.4, pp.57-66, 2019.DOI: 10.5815/ijem.2019.04.05

[9] Sujata Bhavikatti, Sadanand P, Mukta Patil, Pradeep Vibhuti, Shailaja S.Mudengudi. "Automated Roof Top Plant Growth Monitoring System in Urban Areas", International Journal of Engineering and Manufacturing (IJEM), Vol.9, No.6, pp.14-23, 2019. DOI: 10.5815/ijem.2019.06.02

[10] McNally, Amy, Kristine Verdin, Laura Harrison, Augusto Getirana, Jossy Jacob, Shraddhanand Shukla, Kristi Arsenault, Christa Peters-Lidard, and James P. Verdin. "Acute Water-Scarcity Monitoring for Africa." Water 11, no. 10 (2019): 1968.

[11] Anatolii I. Zhuchenko, Liudmyla V. Osipa, Evgeniy S. Cheropkin,"Design Database for an Automated Control System of Typical Wastewater Treatment Processes", International Journal of Engineering and Manufacturing(IJEM), Vol.7, No.4, pp.36-50, 2017.DOI: 10.5815/ijem.2017.04.04

[12] Shamshiri, Redmond Ramin, James W. Jones, Kelly R. Thorp, Desa Ahmad, Hasfalina Che Man, and Sima Taheri. "Review of optimum temperature, humidity, and vapour pressure deficit for microclimate evaluation and control in greenhouse cultivation of tomato: a review." International agrophysics 32, no. 2 (2018): 287-302.

[13] Lakhiar, Imran Ali, Gao Jianmin, Tabinda Naz Syed, Farman Ali Chandio, Noman Ali Buttar, and Waqar Ahmed Qureshi. "Monitoring and control systems in agriculture using intelligent sensor techniques: A review of the aeroponic system." Journal of Sensors 2018 (2018).

[14] Akin cellatoglu, Balasubramanian Karuppanan "Remote Sensing and Control for Establishing and Maintaining Digital Irrigation”, International Journal of Advanced Information Technology, Vol. 2, No.1, pp.11-25, 2012.

[15] Singh, Avtar, Navneet Aggarwal, Gurpreet Singh Aulakh, and R. K. Hundal. "Ways to maximize the water use efficiency in field crops-A review." Greener Journal of Agricultural Sciences 2, no. 4 (2012): 108-129.

[16] Giri, Manish, and Dnyaneshwar Natha Wavhal. "Automated intelligent wireless drip irrigation using linear programming." International Journal of Advanced Research in Computer Engineering \& Technology (IJARCET) Vol. 2, no. 1 (2013). 
[17] El Marazky, Mohamed Said Abdall, Fawzi Said Mohammad, and Hussein Mohamed Al-Ghobari. "Evaluation of soil moisture sensors under intelligent irrigation systems for economical crops in arid regions." American Journal of Agricultural and Biological Sciences 6, no. 2 (2011): 287-300.

[18] Boutraa, Tahar, Abdellah Akhkha, Abdulkhaliq Alshuaibi, and Ragheid Atta. "Evaluation of the effectiveness of an automated irrigation system using wheat crops." Agriculture and Biology Journal of North America 2, no. 1 (2011): 80-88.

[19] Dong, Xin, Mehmet C. Vuran, and Suat Irmak. "Autonomous precision agriculture through integration of wireless underground sensor networks with center pivot irrigation systems." Ad Hoc Networks 11, no. 7 (2013): 1975-1987.

[20] Dursun, Mahir, and Semih Özden. "An efficient improved photovoltaic irrigation system with artificial neural network based modeling of soil moisture distribution-A case study in Turkey." Computers and electronics in agriculture 102 (2014): 120-126.

[21] EVSTATIEV, Boris, Katerina GABROVSKA-EVSTATIEVA, Dimitar TRIFONOV, and Nikolay MIHAILOV. "Solar energy potential to power the irrigation of orchards in Bulgaria." In Proceedings of the 47th International Symposium, Actual Tasks on Agricultural Engineering, 5-7 March 2019, Opatija, Croatia, pp. 213-221. University of Zagreb, Faculty of Agriculture, 2019.

[22] Pardo Picazo, Miguel Ángel, Juan Manzano Juárez, and Diego García-Márquez. "Energy consumption optimization in irrigation networks supplied by a standalone direct pumping photovoltaic system." Sustainability 10, no. 11 (2018): 4203.

[23] Pallavi Singla, Prashant Jain, Roop Pahuja,"Implementation of Gas Scathe Admonisher and Control System Prototype", International Journal of Engineering and Manufacturing (IJEM), Vol.7, No.2, pp.23-38, 2017.DOI: 10.5815/ijem.2017.02.03

[24] Salihu O. Aliyu, Innocent O. Agbo, Saidu Muslim,Elizabeth N. Onwuka,"Multi-Sensor Approach for Monitoring Pipelines", International Journal of Engineering and Manufacturing(IJEM), Vol.7, No.6, pp.59-72, 2017.DOI: 10.5815/ijem.2017.06.06

[25] Nandini M.Naik, Girish S.Kulkarni, K.B.Prakash,"Analysis and Treatment of Water Contaminated by Petroleum Products", IJEM, vol.4, no.5, pp.1-11, 2014.DOI: 10.5815/ijem.2014.05.01

Authors' Profiles

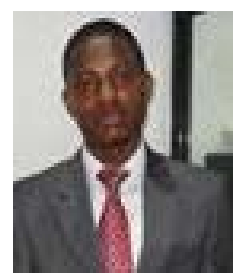

S. Akwu is a First-degree holder in computer and communications engineering (B.Eng.) from the Department of Computer and Communications Engineering, Abubakar Tafawa Balewa University Bauchi (ATBU), Nigeria. His focus is on wireless communication, Embedded systems, and microelectronic system. 


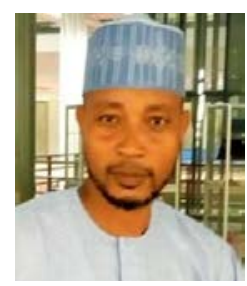

U. I. Bature is currently a Ph.D. Candidate in the Department of Electrical Engineering, Universiti of Teknologi Petronas (UTP) Malaysia. He received a B.Eng. Computer Engineering from Bayero University Kano (BUK), Kano city, Nigeria, and degree of Master of Engineering (Electrical - Computer and Microelectronic system) from Universiti Teknologi Malaysia (UTM), Skudai, Johor Bahru, Malaysia. He is currently a lecturer in the Department of Computer and Communications Engineering, Abubakar Tafawa Balewa University Bauchi (ATBU), Nigeria. His research interest includes Image processing, Nano-material design, embedded systems, and Biomedical Systems.

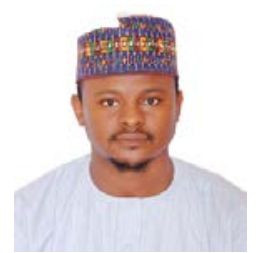

K. I. Jahun received a B.Eng Electrical and Electronics Engineering from the Federal University of Technology, Yola Adamawa State, Nigeria. M.Eng (Communication Engineering) from Universiti Tun Hussein Onn Malaysia, Parit Raja Johor Malaysia. Currently a Lecturer in the Department of Computer and Communications Engineering, Abubakar Tafawa Balewa University, Bauchi, Nigeria. His research interest includes communication systems, Microwave, Antenna, and Propagation.

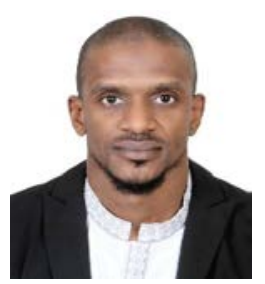

M. A. Baba obtained his first degree in 2010 from Abubakar Tafawa Balewa University Bauchi, Nigeria (ATBU) in Electrical/Electronics Engineering. He further received his MSc. Degree in Information Technology from the University of Wolverhampton, U.K, in 2013. He is currently pursuing his Ph.D. with Advanced Radio Frequency and Microwave Research Group (ARFMG), School of Electrical Engineering, Faculty of Engineering, University Teknologi Malaysia UTM, Malaysia. His areas of research interest include metamaterial antenna for MIMO applications and have been with ATBU Bauchi since

2014 as a lecturer.

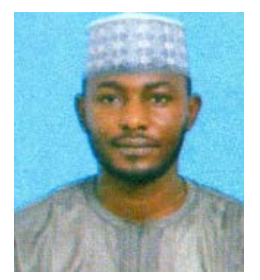

A. Y. Nasir is currently a Ph.D. Student, Laboratory of Computer Science, Robotics and Microelectronics (LIRMM), Universite de Montpellier, France. He received a B.Eng. Computer Engineering from Bayero University Kano (BUK), Kano city, Nigeria, and degree of Master of Engineering (Electrical-Computer and Microelectronic system) from Universiti Teknologi Malaysia (UTM), Skudai, Johor Bahru, Malaysia. He is currently a lecturer in the Department of Computer and Communications Engineering, Abubakar Tafawa Balewa University Bauchi (ATBU), Bauchi, Nigeria. His research interest includes Embedded systems, System on Chip (SoC), Image processing.

How to cite this paper: S. Akwu, U. I. Bature, K. I. Jahun, M. A. Baba, A. Y. Nasir. "Automatic plant Irrigation Control System Using Arduino and GSM Module ", International Journal of Engineering and Manufacturing(IJEM), Vol.10, No.3, pp.12-26, 2020. DOI: 10.5815/ijem.2020.03.02 